\title{
THE
}

$11-7-2013$

\section{Virtuality as Place and Process}

Nikhilesh Dholakia

University of Rhode Island, transmod@uri.edu

Ian Reyes

University of Rhode Island, ianreyes@uri.edu

Follow this and additional works at: https://digitalcommons.uri.edu/com_facpubs

The University of Rhode Island Faculty have made this article openly available.

Please let us know how Open Access to this research benefits you.

This is a pre-publication author manuscript of the final, published article.

Terms of Use

This article is made available under the terms and conditions applicable towards Open Access Policy Articles, as set forth in our Terms of Use.

\section{Citation/Publisher Attribution}

Dholakia, Nikhilesh and lan Reyes. "Virtuality as Place and Process." Journal of Marketing Management, vol. 29, no. 13-14, 2013, pp. 1580-1591. http://dx.doi.org/10.1080/0267257X.2013.834714

Available at: http://dx.doi.org/10.1080/0267257X.2013.834714 


\section{"Virtuality as Place and Process"}

Nikhilesh Dholakia

College of Business Administration, University of Rhode Island

$$
\text { Ian Reyes }
$$

Harrington School of Communication and Media, Department of Communication Studies, University of Rhode Island

This is a pre-publication manuscript of Nikhilesh Dholakia \& Ian Reyes (2013) Virtuality as place and process, Journal of Marketing Management, 29:13-14, 1580-1591: http://dx.doi.org/10.1080/0267257X.2013.834714 


\begin{abstract}
$\underline{\text { Abstract }}$
Virtual worlds are conventionally understood as representational places, or alternate realities more or less set apart from the real world. However, in considering new and emergent technologies, such as social media sites and augmented reality devices, which complicate any easy distinction between virtual and real, we contend that virtuality should also be understood as a matter of process, or the means by which virtualisation is realised. Focusing on theorisations clustered around Baudrillard's theory of simulation, we compare Baudrillardian concepts to other possible theorisations in order to shed light on practices including transmediation and information management at the dawning of the age of Big Data.
\end{abstract}

Keywords: virtual reality, comparative theory, place, process, transmedia, digital

\title{
$\underline{\text { Introduction }}$
}

Considering the technical capabilities and social implications of new and emerging communication technologies, it is necessary to consider how virtual worlds have been theorised and to inquire as to whether those theorisations can continue to illuminate virtuality. Researchers in many fields, including marketing (e.g., Frrat, Dholakia, \& Venkatesh, 1995; Firat \& Ulusoy, 
2011; Fuat \& Dholakia, 2006), have worked with Baudrillardian ideas of the virtual as a simulation of the real; thus we turn to Baudrillard to inform our commentary on virtuality as a concept and as a fact of life. Nonetheless, it is also important to acknowledge that virtuality today is not what it once was, and in that regard theories of the virtual require some reconsideration and renovation. In particular, we find that the upswing in digital processes promising to integrate, rather than supplant, the real with the virtual (e.g., social networking sites, augmented reality technologies) necessitate thinking of virtual worlds not only as simulational places that are other to the real, but as an ensemble of social, technical, and market relations coursing through all areas of present-day existence.

In this, we follow Robbins (1996), who found early in the digital age that

[t]hrough the development of new technologies, we are, indeed, more and more open to experiences of de-realization and delocalization. But we continue to have physical and localized existences. We must consider our state of suspension between these conditions. We must de-mythologize virtual culture if we are to assess the serious implications it has for our personal and collective lives. Far from being some kind of solution for the world's problems - could there ever be a 'solution'? - virtual inversion simply adds to its complexities. (Robbins, 1996, p. 92)

In sum, our conception of virtuality seeks to account for these complexities by equalising and sustaining this state of suspension. In so doing, we 
demythologise virtual culture, arguing that virtuality should be conceived in terms of its processes for re-realisation and re-localisation, not merely as places of de-realisation or de-localisation.

In the commentary that follows, Baudrillard figures as the keystone for an arc of theories of virtuality spanning twentieth-and twenty-first-century efforts to comprehend the role of new media technologies in the construction of reality. Ultimately, we hold the perspective that any question about virtual worlds is as much a question about the real world, and that categories like 'virtual' and 'real' are historically and materially contingent. Although we will dwell on some subtle differences between theories of virtuality, it is nonetheless possible, and expedient, to chart some examples of virtual places and their related processes - which will be addressed in more detail below - in terms of their degrees of virtuality from low, or considered more real, to high, or considered more unreal.

While our project begins with the challenge of theorising this entire field - accounting for the coexistence of varying degrees of real and virtual places and processes - our central concern is not what is more or less real, but how, in the present epoch's configuration of virtuality, processes are becoming as prominent and impactful as places, or even more so. The problem we identify is that virtual processes are relatively under-represented in theories of virtual 
worlds, and so this parsing of place from process is intended to both contextualise and inform place-oriented research, as well as paving a route toward more distinctly process-oriented matters.

\section{Unfolding Virtualities}

Virtualisation and the co-constitutive reciprocity between real and virtual is, in some respects, an age-old problem (e.g., Plato's Sophist). In this sense, virtuality is a timeless theoretical conundrum as well as a historically situated social issue. In the present epoch, the key distinction between the situation of early and mid twentieth-century writers and that of the late twentieth and early twenty-first century is between mechanical, analogue, brickand-mortar-bound technologies and electronic, digital, networked technologies; the on-screen/off-screen split of early modern theories and the online/offline split of more recent theories are different historical iterations of the same kind of techno-social (re)configurations. For marketing, the crux of the matter begins with the industrialisation of virtuality and the social implications of a (real) world saturated with less-than-real products, experiences, and spaces for consumption. Such is the key to Frankfurt School criticism, as in Adorno and Horkheimer's ‘The Culture Industry’:

The whole world is made to pass through the filter of the culture industry. The old experience of the movie-goer, who sees the 
world outside as an extension of the film he has just left (because the latter is intent upon reproducing the world of everyday perceptions), is now the producer's guideline. The more intensely and flawlessly his techniques duplicate empirical objects, the easier it is today for the illusion to prevail that the outside world is the straightforward continuation of that presented on the screen. This purpose has been furthered by mechanical reproduction since the lightning takeover by the sound film. (Adorno \& Horkheimer, 1944/1999, p. 35)

Walter Benjamin's (1936/2002) famed 'Work of Art' essay likewise dwells on the proliferation of mass media at the expense of more real, or authentic life. And this Frankfurt sensibility extended through early theorists of the digital age, who similarly considered virtuality as the outcome of highly technologised forms of representation (e.g., Eco, 1973/1990; Murray, 1997; Rheingold, 1991; Stone, 1991, 1996; Tomas, 1996). Maintaining the distinction between real and virtual - particularly peoples' experiences of alienation from virtual worlds - is absolutely necessary for coming to terms with the aesthetics of virtuality, including qualities of interactivity, presence, and immersion found in massively multiplayer online (MMO) games like World of Warcraft and Everquest, and avatar-based social platforms such as Second Life and Habbo Hotel (Lombard \& Ditton, 1997; Reyes \& Adams, 2010; Riva, Davide, \& Ijsseisteijn, 2003).

While theories conceiving virtualisation as a matter of representing or creating places like these are justifiably inspired and facilitated by earlier work on film, television, and music as virtual worlds, it is necessary to also consider 
that the digital realm is not merely a collection of separate worlds, discreet nodes, or otherwise unrelated communication platforms. Each is constructed, supported, connected, and surrounded by less easily observed processes of virtualisation (e.g., network protocols, tracking cookies, game engines). Before pressing on with this point, however, it is first necessary to lay more of a foundation for such a discussion. Thus we need to dwell on virtuality in general before further refining these specifics.

Virtual worlds, especially the highly representational and narratological types - those we refer to as places rather than processes - are to our day and age what Disneyland was within Baudrillard's schema. Indeed, of Disneyland, Baudrillard wrote:

Disneyland is presented as imaginary in order to make us believe that the rest is real, when in fact all of Los Angeles and the America surrounding it are no longer real, but of the order of the hyperreal and of simulation. It is no longer a question of a false representation of reality (ideology), but of concealing the fact that the real is no longer real, and thus of saving the reality principle. (Baudrillard,1981/1988, p. 172)

In a similar vein, the obviously constructed, clearly simulative aspects of digital places like video games and avatar-based social networks serve to deny as well as sustain the equally virtual reality of nearly all aspects of contemporary life. Just as the exotica of Disneyland mirrored, intensely, the state of late twentieth- 
century social existence in general, so do the exotica of Second Life or Everquest mirror, intensely again, the permeating virtuality of the present day. However, for Baudrillard and those likeminded, there seems to be a misplaced yearning for the past, which 'betray[s] a nostalgia for a prelapsarian moment when there was a real. But the real has always been mediated through information cultures and through narrative' (Landsberg, 2000, p. 192). Nostalgic though it is, in fairness to Baudrillard's position it must be recognised that the dominating influence of global capital capable of affecting media systems, and therefore social reality, is the keystone of his theory and politics 'even signs must burn' (Baudrillard, 1972/1988, p. 92) - and it is the difference between the status of the real in this as opposed to other historic configurations of information cultures and narratives that matters. But still this does not settle whether the exigent call to theorise (again) virtual worlds brings us to a terrain within or beyond Baudrillard's classic schema.

Paul Virilio's take on Baudrillardian theory as anachronistic, rather than nostalgic, provides a way to move ahead:

I disagree with my friend Baudrillard on the subject of simulation. To the word simulation, I prefer the one substitution. This is a real glass, this is no simulation. When I hold a virtual glass with a data glove, this is no simulation, but substitution. Here lies the big difference between Baudrillard and myself: I don't believe in simulationalism, I believe that the word is already old-fashioned. As I see it, new technologies are substituting a virtual reality for an actual reality. And this is 
more than a phase: it's a definite change. We are entering a world where there won't be one but two realities, just like we have two eyes or hear bass and treble tones, just like we now have stereoscopy and stereophony: there will be two realities: the actual, and the virtual. (Quoted in Wilson, 1994)

Though, as Wilbur (2000) pointed out, the historical implications of this are essentially the same as Baudrillard's ultimate level of simulation - becoming more real than real (p. 55) - we find the difference in Virilio's rhetoric both generative and provocative.

To the extent that virtual worlds have become viable consumptionscapes in and of themselves, 'virtual' cannot mean un-real, less than real, or simulational. Even if there once was a simulational tether to a more real reality, the facticity of virtual markets suggests that the tether is severed, and what is called 'virtual' is not un-real but another reality that can and has substituted for the other. Nevertheless, the original is not eclipsed by its substitute - and this is where Virilio's rhetoric leads to a theorisation that is significantly different from Baudrillard's - but exists alongside the prior reality, creating a single, more information-rich reality, like stereoscopic images and binaural audio. 'Virtual', in this sense, is not the name for the new real poised against the old it is the name for the simultaneous, substitute, stereo terrain resulting from the coexistence of simultaneous reals. As Disneyland reaffirmed one reality through obstructing the view of the latter's construction by revealing that of the former, 
virtual worlds that announce themselves as such serve to distract from the virtuality of the world well outside those narrow bounds, thus simulating/substituting the same obstructive dynamic on the other side of the stereo pair.

Examining virtuality through theoretical lenses developed for the study of artefacts like cinema or amusement parks, however, should be an endeavour undertaken with great care and some trepidation when it comes to marketing. As Sawchuck (1994) found, a bias toward issues of representation, or of virtual places, such as that epitomised by Baudrillard's early work, leads away from the core of the marketing concept, of which representing (qua advertising) is but one element:

Electronic networking and computer software developments create a vast virtual transactional space which invites us to conduct ourselves along programmed potential routes of consumption. [ ... ] While this is a fecund terrain for critical thinking, academic work, including Baudrillard's, tends to revert to discussions of advertising, or the issue of representation, rather than marketing, or the question of circulation. (Sawchuck, 1994, pp. 94-95)

A propensity for reducing things to texts for interpretation, a trait shared by many media theorists, means that marketing is not well represented in common conceptualisations of virtual worlds. Virtual worlds are more than representations or texts - they are also, if not primarily, processes. 
According to Sawchuck (1994), the virtualisation processes central to marketing are polling and surveillance, with the ultimate goal being to document consumers as such and to 'prime' them to take a particular path through information networks (p. 99). For digital and non-digital networks, these processes - documenting and priming consumers - are essential for populating and exploiting consumptionscapes, virtual or otherwise. In the following sections, we will further separate these two related components of virtuality - places and processes - by extending and refining the above theorisations in order to consider whether and to what extent they might help us come to terms with the implications of today's virtual worlds for marketing.

\section{$\underline{\text { Places }}$}

The Disneylands of cyberspace are places that are obviously to some extent removed from, or in suspension with, everyday reality. These are the places ranked high on Table 1. In such worlds - constructed as alternatives to reality - things are more imaginary than real, and consumption in such spaces is also somewhat imaginary. Though real money is often exchanged for in-world (virtual) items, these objects of consumption are not usually thought of as real because their efficacy is tilted to but one information channel of virtuality's parallactic pair (e.g., purchasing a game expansion that includes new weapons 
is not the same as actually purchasing weapons; purchasing custom outfits for an avatar is not the same as buying real garments). Therefore, these tend to be the areas of great interest and anxiety. The sleight of hand substituting one reality for another is obvious in these cases, likely because they attempt the impossible, substituting bits for atoms.

\section{TABLE 1: DEGREES OF VIRTUALITY WITH AFFILIATED PLACES AND} PROCESSES

\begin{tabular}{|c|c|c|}
\hline Degree of Virtuality & Places & Processes \\
\hline \multirow[t]{5}{*}{ High } & $\begin{array}{l}\text { online multiplayer video } \\
\text { games; avatar-based social } \\
\text { platforms }\end{array}$ & $\begin{array}{l}\text { dynamic, real-time } \\
\text { a/v processing; } \\
\text { cloud computing }\end{array}$ \\
\hline & $\begin{array}{l}\text { social networking sites; online } \\
\text { discussion forums }\end{array}$ & $\begin{array}{l}\text { web tracking and } \\
\text { surveillance; } \\
\text { gamification }\end{array}$ \\
\hline & $\begin{array}{l}\text { augmented reality; internet of } \\
\text { things }\end{array}$ & $\begin{array}{l}\text { wireless internet; } \\
\text { RFID; QR codes; } \\
\text { GPS }\end{array}$ \\
\hline & $\begin{array}{l}\text { digital audio/video tools and } \\
\text { products }\end{array}$ & $\begin{array}{l}\text { analog/digital } \\
\text { conversion; MIDI; } \\
\text { DRM }\end{array}$ \\
\hline & cinema, radio, television & $\begin{array}{l}\text { analog } \\
\text { recording/playback, } \\
\text { broadcast; polling; } \\
\text { licensing; } \\
\text { syndication }\end{array}$ \\
\hline Low & novels, comics & $\begin{array}{l}\text { mechanical } \\
\text { printing; } \\
\text { serialization; } \\
\text { subscription }\end{array}$ \\
\hline
\end{tabular}


Negroponte (1995) explained that the new information age relies on turning atoms into digital bits, and predicted that industries that could not easily change atom-based products into bit-based products (e.g., textiles) would be less affected in this age, whereas those for which the change is easy (e.g., the music industry) would see radical upheavals. From this vantage point, it can be seen that highly virtual, substitutive worlds are identifiable by the degree to which products inextricable from atoms are nonetheless digitised. That is, for marketers, virtual places are key sites wherein it is possible to do the impossible - to give digital body to products that might never otherwise manifest digitally. Second Life may be the most well-known platform for this type of activity (sometimes called 'skeumorphism'; Grossman, 2013), though simulational video games have also become quite comfortable with this. The Tiger Woods golf franchise by Electronic Arts, for instance, is a heavily branded game environment marked not only by the imprimatur of the golfer himself, but also by the real-world golf courses, equipment manufacturers, and golfing attire that define the consumptionscape for actual pro golf. What makes such environments less than real, and obviously virtual, is the preponderance of simulation, or of forced equivocation of bits for atoms; only within such a digital Disneyland can an imaginary, digital golf club function as its atom-based counterpart might. 
Yet even classic types of virtual worlds (e.g., movies, video games) are becoming more complex, less tied to a definite place or text, and more integrated into the real information flows of an always-on mediascape marked by multiple points for consumer access. The kaleidoscopic proliferation of channels for digital communication means that marketers are faced with new, daunting challenges presented by multi-screen behaviours (D'heer, Courtois, \& Paulussen, 2012). For the entertainment industry, one effective answer has been to adopt transmedia strategies. Transmedia was first described as follows:

This process of reproducing the postmodernist subject and its dynamic of commercial empowerment is now being intensified and accelerated in home video games, in commercial transmedia supersystems constructed around figures like Teenage Mutant Ninja Turtles, and in multinational corporate mergers like Sony's recent takeover of Columbia Pictures and Matsushita's acquisition of MCA/Universal. In these expanding networks of synergy, connectivity, collectability, restructuring, new world orders (and other postmodernist buzzwords), children, corporations, and countries are learning that transmedia intertextuality is a powerful strategy for survival. (Kinder, 1991, p. 38)

In the contemporary new media environment, opportunities for transmediation are plenty, and marketers are reaching levels of sophistication and coordination dwarfing transmedia strategies of the 1990s. More than ever, transmedia offer more comprehensive, adaptive, and deep experiences with virtual worlds, advancing far beyond mere synergy across products. Today's transmedia, exemplified by franchises such as Halo - which began as a console video game 
but now spans comics, novels, and film and television - show that a 'world' is very thin if it consists of only a single place; a truer, fuller, more compelling world is made from a collection of connected places.

Explaining how this is not old-fashioned synergy or licensing across different vendors or product classes, Halo's Franchise Manager stated:

When Microsoft founded the studio to take care of Halo it was very important to us that everything counts in the universe, that there are no side tracks or lesser tracks for the fiction, the events that take place in the novels are a meaningful and a real part of our universe because if fans are going to spend their time and spend their money to kind of consume those experiences to get in and enjoy them, then if we tell them well that doesn't count that kind of sucks as a fan. (Grace \& Troisi, 2012)

While emphasising that the Halo line of console games remains the 'tent pole' of the franchise, or that toward which other texts are intended to drive consumers, Grace \& Troisi (2012) recognise that transmediation can be effective only if each and every branch from that central text, no matter the medium, can also stand on its own. This franchise thus illustrates Henry Jenkins' 'ideal form' of transmedia in that each product is relatively autonomous yet nonetheless directs consumers back to the field of products and services related with this brand/world:

In the ideal form of transmedia storytelling, each medium does what it does best - so that a story might be introduced in a film, expanded through television, novels, and comics, and its world might be explored and experienced through game play. Each 
franchise entry needs to be self-contained enough to enable autonomous consumption. That is, you don't need to have seen the film to enjoy the game and vice-versa. As Pokémon does so well, any given product is a point of entry into the franchise as a whole. (Jenkins, 2003)

Through transmedia enterprises like Halo and Pokémon, consumers are not just 'interacting' with virtual worlds by seeing, for instance, plots from a comic book adapted for television, or playing through scenes from a movie in a game. Thanks to coordinated quality control across products, or points of access, every component serves to expand, rather than repeat, the narrative, thus expanding the world by proliferating its territories.

Closer consideration of transmedia, which is beyond the scope of our present piece, would also illuminate the range of products and services, from selling permissions to increasing ad space, defining the broader market context for such polymorphic virtual places. Through our brief review, however, one should get a sense of how transmedia strategies address matters of circulation, or how to populate virtual places with consumers, by increasing points of access to a central product/place in a way that also expands and enhances the virtual worlds thereupon constructed. However, the growth of virtual places through transmediation is possible and desirable only due to corresponding processes of virtuality, toward which we next turn. 


\section{Processes}

To begin to tease process away from place, consider an electronic dance music (EDM) track. A music recording of any type is a kind of virtual place, an artificial soundscape. But with electronic music in particular, there is very little reference to or reliance on a reality outside of the digital media required for the production, circulation, and consumption of that music. EDM is typically created through musical instrument digital interface (MIDI) programming (virtual performance), recorded and mixed with a digital audio workstation (virtual studio and instruments), sold through iTunes (virtual record store), popularised through podcasts (virtual radio), then purchased with a credit card (virtual money) depositing to a PayPal account (virtual bank), the profits from which may then be speculatively invested in Bitcoin (virtual currency).

While it is true that there is an irreducible bedrock of atoms necessary for virtualisation (e.g., computer hardware), these digital products and services supplant what they simulate and, in that way, substitute for their earlier, ostensibly more real equivalents. In a Baudrillardian sense, this is what those Disneyland-esque virtual places distract from - namely the fact that while the online world may be a simulated reality, this does not mean that it cannot become reality itself. Or, in Virilio's terms, it is another real, not other than real. These are virtual not because they de-realise music, they are virtual because 
they re-realise it, or relocate its ontological centre of gravity through digital processes. An EDM song is not a simulated version of its analogue equivalent; it is the market thing itself, the object of both production and consumption. Moreover, the lifecycle of such products is almost entirely virtual in that few 'real' pieces of technology (e.g., microphones, keyboards, tape, duplication facilities) are needed because their 'virtual' equivalents can well substitute. However, the bad news, as noted previously, is that academic research on virtuality tends toward the study of representations, or virtual worlds, as places, more than these processes of virtualisation surrounding and supporting much more than representational worlds, indeed affecting social and material reality - the world writ large - in ways that may be more impactful than virtual places. Nonetheless, the good news is that marketing researchers are uniquely poised to illuminate the processual aspects of virtuality, those seemingly intangible connections between parallactically paired realities. Such work might reach beyond the virtualisation of products and spaces for their consumption to also consider the virtualisation of consumers themselves (Sawchuck, 1994; Zwick \& Dholakia, 2011) or even of managers and personnel (Boje, 1995; Boje \& Rhodes, 2005). Though it is impossible herein to fully unpack the constellation of processes identified around even just this one type of virtual product, EDM music, the main thrust of any process-oriented theorisation of 
virtuality points towards the necessity of better understanding the production, circulation, and consumption of data, the essence of the present (digital) information age.

In this, one undoubtedly hears echoes of the familiar refrain, 'data is the new oil'. The saying perfectly expresses the global situation of successfully substitutive processes. However, it also obscures as much as it reveals. Data is only the new oil in a structural sense. Of course, fossil fuel industries continue to exist and continue to have massive social and economic impacts, not to mention environmental impacts. And, unlike natural resources, data is neither inherently scarce nor easy to control; therefore marketers must engage and intervene with data processes much more directly than they might with an oil refinery. As the era of big data is heralded, relatively little is known about the social, economic, and environmental impacts of the processes making possible data's ascendancy. Yet data's move to the centre of a new socio-economic reality has been enabled by the success of virtual places like social networking sites and online multiplayer video games, exotic Disneyland-esque spectacles, which exist largely as the most visible and enjoyable cogs in much larger processes of virtualisation (e.g., 'free' sites that gather and sell user data and/or advertising space). 
The fact that data is a socio-technical, and not natural, resource fuels the questions central to Lanier's (2013) Who Owns the Future? Social and economic power, in the age of big data, go to those who control the most powerful data technologies - 'siren servers' in Lanier's language. The social construction of this new most precious resource means that the value of data is precarious and contestable, which has implications for everything built upon it, relying as much on market (de)regulation as on technological innovation:

If network technology is supposed to be so good for everyone, why has the developed world suffered so much just as the technology has become widespread? Why was there so much economic pain at once all over the developed world just as computer networking dug in to every aspect of human activity, in the early 21 st century? Was it a coincidence? (Lanier, 2013, pp. 53-54)

Interestingly, one of the roots of the global economic crisis comes from a problem of virtual processes: 'The big kinds of computation that have made certain other industries like music "efficient" from a particular point of view were applied to finance, and that broke finance. It made finance stupid' (Lanier, 2013, p. 54). Regardless, for others, hopes run high for the potential benefits of exporting processes from virtual worlds to the real world.

McGonigal (2011) advocates for a process of real/virtual hybridisation often called 'gamification'. Noting the extraordinary popularity of virtual places like online video games, she argues not for a proliferation of virtual places for 
non-game purposes (e.g., Second Life). Rather, she argues for a proliferation of the processes that make these game worlds compelling:

Gamers want to know: Where, in the real world, is that gamer sense of being fully alive, focused, and engaged in every moment? Where is the gamer feeling of power, heroic purpose, and community? Where are the bursts of exhilarating and creative accomplishment? Where is the heart-expanding thrill of success and team victory? While gamers may experience these pleasures occasionally in their real lives, they experience them almost constantly when they're playing their favorite games. (McGonigal, 2011)

For McGonigal (2011), the ability to extract and export game processes is crucial for, what she terms, the 'engagement economy'. That is more than generating mere attention; it is creating and sustaining emotional investments with a product, brand, or organisation. Yet in light of Lanier's cautionary tale of finance's failed transplant of virtual processes from the music industry, any attempt to transplant virtual processes should be pursued with great care, as they do much more than affect data; they affect reality itself.

\section{Concluding Observations}

New media technologies consistently converge with and remediate each other (Bolter \& Grusin, 2000). For marketers and business strategists, this means that virtual places and processes create opportunities and challenges of entering into agile and complex dances that intermix devices, content streams, 
enticements, digital rights, and (hopefully) payments. Yet despite increasing media convergence and connectivity, the means for engaging with digital products and services remain largely in silos. Competitive rivalries of telecom networks, operating systems, audiovisual display capabilities, bandwidth limitations, licensing agreements, and several other factors define the contours of virtuality on the whole.

In the present configuration, the promised smooth, seamless, multiformat, multi-device, multi-platform, multi-media virtual landscape, it turns out, is a rough and forbidding terrain with visible as well as latent fissures, chasms, and quicksand-pits. For example, even simple acts of seamlessly porting a music track from a home computer to a smartphone to a video chat to a car stereo to a poolside boombox are anything but simple. Yet this is what makes successful transmedia enterprises noteworthy. Transmediation is essentially a marketing strategy designed to overcome the limits inherent in contemporary processes of virtualisation. The virtual worlds created and sustained by transmediation consist of multiple media needing little or no technological connectivity between places (e.g., the novel can be a paperback yet still 'connected' to the online game), as long as the franchise's properties are well managed. 
Still, many of the latest and most potentially transformative developments in virtuality - social media, augmented reality devices, geolocative services - have nothing to do with creating alternate worlds and everything to do with adding another layer of (virtual) reality to everyday (real) life. Thus, the question of virtual places is becoming a 'last generation' one as issues deriving from the spread of virtual processes into everyday life come to the fore. Having noted that marketers and business strategists have successfully found ways to realise the potential of new media while simultaneously having to overcome their technical and institutional limits, it is likely that the principles of transmedia strategies will lead to new processes facilitating greater connectivity where they may now be none. But then there are the less consumer-facing processes and products of big data undergirding all of this virtuality. We are only now beginning to come to terms with the implications of this more radical form of virtualisation, which is, definitively, less bound to place yet more centrally controlled, less easily observed yet more easily engaged, and, perhaps, more insidious than earlier forms of virtuality, especially if we do not more critically study its processes.

\section{$\underline{\text { References }}$}


Adorno, T., \& Horkheimer, M. (1944/1999). The culture industry:

Enlightenment as mass deception. In S. During (Ed.), The cultural studies reader (2nd ed., pp. 32-41). New York, NY: Routledge.

Baudrillard, J. (1972/1988). For a critique of the political economy of the sign.

In M. Poster (Ed.), Jean Baudrillard: Selected writings (pp. 57-97).

Stanford, CA: Stanford University Press.

Baudrillard, J. (1981/1988). Simulacra and simulations. In M. Poster (Ed.), Jean

Baudrillard: Selected writings (pp. 166-184). Stanford, CA: Stanford University Press.

Benjamin, W. (1936/2002). the work of art in the age of its technological reproducibility. In M. W. Jennings and H. Eiland (Eds.), Walter Benjamin: Selected writings (Vol. 2, pp. 101-133). Cambridge, MA: Belknap.

Boje, D. M. (1995). Stores of the storytelling organization: A postmodern analysis of Disney as 'Tamara-land. Academy of Management Journal, 38(4), 997-1035. doi:10.2307/256618

Boje, D. M., \& Rhodes, C. (2005). The virtual leader construct: The mass mediatization and simulation of transformational leadership. Leadership, 1(4), 407-428. doi:10.1177/1742715005057232 
Bolter, J. D., \& Grusin, R. (2000). Remediation: Understanding new media. Cambridge, MA: MIT Press.

D’heer, E., Courtois, C., \& Paulussen, S. (2012, July 4-6). Everyday life in (front of) the screen: The growth of multiple screen technologies in the living room context. EuroITV’12, Berlin.

Eco, H. (1973/1990). Travels in hyperreality. New York, NY: Mariner.

Firat, A. F., Dholakia, N., \& Venkatesh, A. (1995). Marketing in a postmodern world. European Journal of Marketing, 29(1), 40-56. doi:10.1108/03090569510075334

Firat, A. F., \& Ulusoy, E. (2011). Living a theme. Consumption Markets \& Culture, 14(2), 193-202. doi:10.1080/10253866.2011.562020

Fuat, F. A., \& Dholakia, N. (2006). Theoretical and philosophical implications of postmodern debates: Some challenges to modern marketing. Marketing Theory, June 6, 123-162. doi:10.1177/1470593106063981

Grace, K., \& Troisi, A. (2012). Building Transmedia Worlds in Halo 4. Presented at annual meeting of the Game Developers' Conference. Retrieved from http://www.gdcvault.com/ play/1016603/BuildingTransmedia-Worlds-in-Halo

Grossman, L. (2013, June 3). Flatland: Should the virtual world try to look like the real one?,Time. 
Jenkins, H. (2003). Transmedia Storytelling. MIT Technology Review. Retrieved from http://www.technologyreview.com/news/401760/transmediastorytelling/page/3/

Kinder, M. (1991/1993). Playing with power in movies, television, and video games: From Muppet babies to teenage mutant ninja turtles. Berkeley: University of California Press. Landsberg, A. (2000). Prosthetic memory: Total recall and blade runner. In D. Bell and B. M.

Kennedy (Eds.), The cybercultures reader (pp. 190-201). New York, NY: Routledge. Lanier, J. (2013). Who owns the future? New York, NY: Simon and Schuster.

Lombard, M., \& Ditton, T. (1997). At the heart of it all: The concept of presence. Journal of Computer Mediated Communication, 3(2). International Communication Association. doi:10.1111/j.10836101.1997.tb00072.x

McGonigal, Jane. (2011). Reality is broken: Why Games make us better and how they can change the world (Paperback Reprint Edition). New York, NY: Penguin.

Murray, J. (1997). Hamlet on the Holodeck: The future of narrative in cyberspace. New York, NY: Free Press. 
Negroponte, N. (1995). Being digital. New York, NY: Alfred A. Knopf.

Plato (1921). Theatetus/Sophist (H. N. Fowler, Trans). Cambridge, MA: Loeb.

Rheingold, H. (1991). Virtual reality: The revolutionary technology of computer-generated virtual worlds, and how it promises to transform society. New York, NY: Touchstone.

Reyes, I., \& Adams, S. (2010). Screening play: Rules, wares, and representations in 'realistic' video games. Eludamos, 4(2), 149-166.

Riva, G., Davide, F., \& Ijsseisteijn, W. A. (2003). Being there: Concepts, effects and measurements of user presence in synthetic environments. Amsterdam: IOS Press.

Robbins, K. (1996/2000). Cyberspace and the world we live in. In D. Bell, and B. M. Kennedy (Eds.), The cybercultures reader (pp. 77-95). New York, NY: Routledge.

Sawchuck, K. (1994). Semiotics, cybernetics, and the ecstasy of marketing communications. In D. Kellner (Ed.), Baudrillard: A critical reader (pp. 89-116). Cambridge, MA: Blackwell.

Stone, A. R. (1991). Will the real body please stand up? In M. Benedikt (Ed.), Cyberspace: First steps (pp. 81-118). Cambridge, MA: MIT Press.

Stone, A. R. (1996). The war of desire and technology at the close of the mechanical age (pp. 81-118). Cambridge: MIT Press. 
Tomas, D. (1996). Virtual reality and the politics of place. History and Anthropology, 9(2-3), 327-357. doi:10.1080/02757206.1996.9960884 Wilbur, S. P. (2000). An archaeology of cyberspaces: Virtuality, community, identity. In D. Bell, and B. M. Kennedy (Eds.), The cybercultures reader (pp. 44-55). New York, NY: Routledge. Wilson, L. (1994) Cyberwar, god and television: Interview with Paul Virilio. Ctheory. December 1. Retrieved from http://www.ctheory.net/articles.aspx?id=62

Zwick, D., \& Dholakia, N. (2011). Strategic database marketing. In L. Penaloza, and N. Toulouse (Eds.), Marketing management: A cultural perspective (pp. 443-458). London: Routledge. 
